\title{
Risk-Taking in the New Zealand Bush: Issues of Resilience and Wellbeing
}

\author{
Amanda Bateman ${ }^{1)}$ \\ Jane Waters \\ Swansea University $\quad$ University of Wales Trinity Saint David
}

\begin{abstract}
This article discusses a single case analysis of teacher-child interactions on an everyday bush walk in New Zealand. It uses a combination of the Leuven wellbeing scale (Laevers, 2000) and a conversation analysis approach to explore how children and teachers attend to specific features of the outdoor environment in a way that encourages risk-taking and builds resilience through problem solving. The collaborative achievement of the activities between the pre- school teacher and the fouryear-old children are discussed as an important and necessary aspect of the interactions, which we suggest may represent physical sustained shared thinking, for supporting wellbeing whilst building resilience and risk-taking. Implications for future practice are considered with regard to implementation of early childhood curricula.
\end{abstract}

Keywords: outdoor play, risk taking, conversation analysis, resilience

Corresponding author, ${ }^{1)}$ a.j.bateman@swansea.ac.uk 


\section{The Benefits of Outdoor Play}

The importance of children's regular access to the outdoor environment is well documented (Waller et al., 2017). Within this literature, outdoor play is valued for the affordances it provides for children to enact agency in their enquiry (Maynard, Waters, \& Clement, 2013; Waters, 2011; Waters \& Bateman, 2013), perceive themselves as competent learners (Maynard et al., 2013), and engage in risk taking (Little, Wyver, \& Gibson, 2011; Sandseter, 2007, 2009). However, less is known about how such affordances are related to the development of resilience as an aspect of children's wellbeing (e.g. Newman, 2004) and how opportunities for enacting resilience are co-produced through conversational exchanges between teachers and children within the outdoor environment.

\section{Wellbeing and Resilience}

There are many different definitions of resilience, but all refer to the capacity of the individual to demonstrate the personal strengths needed to cope with some kind of challenge, hardship, or adversity. Noble and McGrath (2012) provide a valuable overview of research and thinking regarding wellbeing and resilience; they report that since the turn of the century, there has been a gradual conceptual shift in both research and community/school practices away from the concept of children and young people's 'welfare', which has a focus on support available during distress towards the concept of "wellbeing and resilience" (p. 17). We have adopted the definition of wellbeing presented by Noble and McGrath as "an overarching term that encapsulates an individual's quality of life, happiness, satisfaction with life and experience of good mental and physical healtt" (p.17). It involves four components:

- positive affect (an emotional component)

- resilience (a coping component)

- perceived satisfaction with relationships and other dimensions of one's life (a cognitive component)

- effective functioning and/or the maximising of one's potential (a performance component) 
In this paper, we are interested particularly in the 'coping component', which is resilience. In their review, Noble and McGrath (2012) explain that the constructs of wellbeing and resilience are closely related and that "most definitions of wellbeing incorporate some reference, either explicit or implied, to the capacity of the individual to be resilient" (p. 19). Both constructs represent "a shift in perspective from a deficit model of young people 'at risk' to a model that focuses on the personal strengths and environmental factors that help young people withstand high levels of 'risk' and, in many cases, flourish" (p.19).

The construct of resilience emerged from the work of researchers who undertook longitudinal developmental studies of 'at-risk' and/or traumatised children and identified that some children thrive against the odds. Resilience, then, can be defined as the capacity to cope and bounce back after encountering negative events, difficult situations, or adversity and to return to almost the same level of emotional wellbeing; also, "being resilient involves seeking new experiences and opportunities and taking risks" (Noble \& McGrath, 2012, p. 20). Risk-taking creates opportunities for success following setback, failure, rejection, or difficulty. Positive relationships with adults, within and beyond the family, are associated with resilience in children; teacher-child relationships that are typically close, warm, and affectionate are also associated with children's social competence at both preschool (Howes \& Ritchie, 1999) and primary school (Pianta, Belsky, Vandergrift, Houts, \& Morrison, 2008) levels. Behaviors that are associated with contributing to higher levels of coping and resilience have been identified through empirical research and include (Noble \& McGrath, 2012):

- Demonstration of social skills that enhance cooperation

- Behavior that reflects empathy and prosocial values

- Emotional regulation such as managing emotions such as anxiety or fear

- Optimistic thinking which includes feeling some sense of competence and control over one's life and having the confidence to persevere when faced with difficulty

- Helpful thinking skills which involve an individual feeling emotionally in control and able to solve problems

- Having a sense of humor

- Goal-setting skills and associated behaviors such as showing initiative, problem 
solving skills, and being resourceful

- Having a sense of autonomy, self-efficacy, and an awareness of one's strengths

- Having a sense of meaning and purpose

We use these behaviors in our considerations as set out below.

\section{Wellbeing in the New Zealand Curriculum}

New Zealand's early childhood education is guided by the curriculum framework Te Whāriki (Ministry of Education [MOE], 1996, 2017). Te Whāriki uses the metaphor of a woven mat that is created by weaving together the four principles - Relationships, Holistic Development, Empowerment, and Family and Community - with the five strands Belonging, Contribution, Communication, Exploration, and Well-being. Te Whāriki is a bicultural document that is specific to the social context of New Zealand, intentionally supporting the learning outcomes and holistic care of children and families of both Maōri and Western descent (MOE, 1996, 2017). The principles and strands are interwoven and so represent the holistic nature of learning from a sociocultural philosophical perspective.

While exploring how the specific strand of Well-being might be supported and enhanced in outdoor play through risk-taking, other strands and principles are also inevitably included. For example, when analyzing children's wellbeing in a specific educational situation such as in outdoor play in this paper, one has to look at the unfolding 'communication' that is occurring between the observed child, their peers, teachers, and other members of their 'family and community' that may be present, and their 'relationships' with the child. We might also look towards the child's 'exploration' of their environment and opportunities for 'contributing', all of which provides a 'holistic' view of the child within their social context.

\section{Supporting Wellbeing through Pedagogical Exchanges}

Sustained shared thinking is a term that was originally used to describe a particular kind of interaction taking place in early years settings deemed to be highly effective in the Effective Provision of Pre-School Education (EPPE) project. The full definition of the term is: 
"Sustained shared thinking" occurs when two or more individuals "work together" in an intellectual way to solve a problem, clarify a concept, evaluate an activity, extend a narrative, etc. Both parties must contribute to the thinking and it must develop and extend the understanding (Sylva, Melhuish, Sammons, Siraj-Blatchford, \& Taggart, 2004, p. 36).

The term has been considered empirically and theoretically since the EPPE project and during the years in which the project was extended as the Effective Pre-school, Primary and Secondary Education (EPPSE) project. The EPPSE project reported that the highly effective early years settings and their associated pedagogies had an impact on the outcomes of the children involved at ages 11,14, and 16, and indeed beyond.

The pre-school influence continued during secondary school. Those who attended high quality pre-school had higher attainment and better social-behavioural development at age $14 \ldots$ By age $16 \ldots$ there were no lasting pre-school effects on social behaviours but attending a pre-school predicted better GCSE results. This positive influence was greater for those who had started at an earlier age (before 3) or who had attended a preschool of high quality (Taggart, Sylva, Melhuish, Sammons, \& Siraj, 2015).

Siraj-Blatchford (2009) sought to explain the nature and development of sustained shared thinking through early childhood and claimed that 'the strongest theoretical resonances' lie with 'Vygotsky (1978) who described a process where an educator supports children's learning within their "zone of proximal development" (p. 77). She claims further resonances with a number of neo-Vygotskian theories, of which we consider the descriptions of pedagogy as 'guided participation' (Rogoff, Mistry, Göncü, \& Mosier, 1993), and as 'scaffolding' (Wood, Bruner, \& Ross, 1976) particularly valuable. The practice of engagement in sustained shared thinking in education-care settings catering for children from 2 to 5 years of age has been closely related to children's emotional wellbeing (Siraj, Kingston, \& Melhuish, 2015).

As the New Zealand's early childhood curriculum emphasizes the importance of empowering children through opportunities for contributing in everyday exchanges with teachers and peers, studying the actions (verbal and non-verbal) of the child in their environment is as important as studying the role of the teacher when investigating issues of supporting wellbeing. Meaning making around such issues as wellbeing can then be seen as a collaborative project where both the teacher and the child have a role, linguistic and 
through actions, in the co-production of interactions. This paper then makes a contribution to the body of work that exemplifies sustained shared thinking as "sustained and shared "moments of activity"' (Leontiev, 1978; Siraj-Blatchford, 2009) and it aligns with a sociocultural approach.

\section{The Project}

The aim of the footage discussed here was to explore teacher-child interactions in everyday situations to reveal how pedagogical moments were collaboratively produced and to what end (Bateman, 2012). Through impromptu conversation, three teachers from one early childhood education and care setting close to the lead author's university showed great interest in exploring their pedagogy further and were interested in participating in a project with this focus. The setting catered for children aged from three months to six years and employed a range of qualified and unqualified staff; out of the three teachers in this project, two were qualified early childhood teachers. Ethical approval was then gained through the lead author's University Ethics Committee and consent was gained from the Director of the crèche, the three teachers, the parents of the children in each of the three teacher's separate classes, and finally the children - this included assent processes for the children and processes by which they could withdraw their assent.

The process of the data collection and analysis involved the three teachers wearing a wireless Bluetooth microphone and being video recorded three times each throughout the year by the lead author as researcher. After each recording, the researcher made supplementary notes about the observation and asked the recorded teacher to identify moments where they felt significant teaching and learning occurred. The researcher then transcribed these identified moments using conversation analysis transcription conventions (Jefferson, 2004). A conversation analysis approach was used to identify the sequential turn- by-turn features of the interactions that worked to co-produce each interaction between teacher and child. Conversation analysis involves transcribing everyday interactions with the premise that there is order at all turns in talk between the participants where interactions are co-produced in orderly and systematic ways (Sacks, Schegloff, \& Jefferson, 1974). The transcriptions adopt pseudonyms throughout. Conversation analysis, 
as a branch of ethnomethodology, offers a framework for understanding the co-production of wellbeing as a social construction in situ, recognizing the contributions children make to the co-production of interactions that they are participants in.

As such, this theoretical perspective aligns well with the sociocultural approach to early childhood education in New Zealand. The detailed CA transcriptions of the teacher's identified moments offered as much detail as possible about the sequential organization of the interaction, helping to tease out the verbal and non-verbal features of the co-production of the situation. During the transcription phase, analytical notes were made, offering an analytical starting point which was then fed back to the teachers at a subsequent meeting. This detailed analysis revealed how the risk-taking episodes were locally managed and offered insight into the role of the teacher that may hold implications for future teaching and learning practice.

\section{Assessing Young Children's Wellbeing: The Leuven Wellbeing Scale}

As this article is specifically interested in exploring how the outdoor interactions between teacher and child helped support wellbeing, the Leuven wellbeing scale (Laevers, 2000) was also incorporated into the analysis here. The inclusion of the Leuven wellbeing scale is in response to their being "little agreement in the research literature on how to best measure child well-being" (Pollard \& Lee, 2002, p. 66). A wide range of measures are employed throughout the research literature including objective measures such as child case history reviews, educational assessments, medical records, and national statistics like rates of death, drug abuse, and suicide. Subjective measures are also used including participants being asked to respond to multiple separate measures such as self-esteem levels, depression, and relationships. Pollard and Lee (2002) make the point that measures that focus on selfesteem and depression levels and claim that these are measures of wellbeing, so they do not actually measure wellbeing since they attend to only one aspect of this complex construct: the psychological/emotional aspect. We should similarly guard against looking for a straightforward or simple way to assess the wellbeing of children in our care. What we might look for is ways of gaining an insight into aspects of children's wellbeing and treating these insights as indicators or signals rather than measures of 'how our children are doing' (Laevers, 2000). 
For younger children, Laevers (2000) argues that we can gain an insight into how our children are doing by considering the linked dimensions of "wellbeing" and "involvement" (p. 24) that children display when engaged in activity:

"when we want to know how each of the children is doing in a setting, we first have to explore the degree to which children feel at ease, act spontaneously, and show vitality and self confidence. All this indicates that their emotional well-being is "OK" and that their physical needs, the need for tenderness and affection, the need for safety and clarity, the need for social recognition, the need to feel competent and the need for meaning and moral value in life, are satisfied ... The concept of involvement refers to a dimension of human activity. Involvement is linked neither to specific types of behaviour nor to specific levels of development" (p. 24).

Children experiencing the highest levels of involvement demonstrate their wellbeing (Anning \& Edwards, 2006) and are disposed to engage in "deep level learning" (Laevers, 2000, p. 20). Wellbeing is described as "feeling at home, being oneself and feeling happy" (Laevers, 1994, p. 5). Involvement concerns "the intensity of the activity, the extent to which one is absorbed" (p. 5) and is linked to Csikszentmihayli (1990)'s state of flow; usually, experienced in young children and in play (Laevers, 2000). Laevers developed the Leuven Involvement Scale to support adult observation of children's activity and allow an evaluation of the extent to which a child is involved in their activity; this is, in turn, being seen as providing an insight into 'how they are doing' or their wellbeing (Laevers, 2000).

\section{Findings}

The findings now describe one of the routine trips to the local bush. The focus is on a continuing episode predominately involving only one of the teachers, but the pedagogy observed is representative of practices across all the teachers involved. Conversation analysis transcription conventions are used to provide as much detail as possible about the interaction and the conversation analysis symbols used to transcribe the data are adapted from Jefferson's conventions described in the study of Sacks et al. (1974). During the trip, there were many interactions that took place between the children and between children and teachers as they engaged with the environmental features. The following transcriptions and their analysis detail a progression in the children's risk taking while crossing the "pit". 
They demonstrate three aspects of the interaction to which we draw attention: (1) sociocultural ways of building resilience; (2) development in children's confidence, and, it is argued here; and (3) contribution to high levels of wellbeing. The specific actions of the early childhood teachers that we draw attention to in our analysis of the transcriptions are positioning and showing an interest.

\section{Positioning}

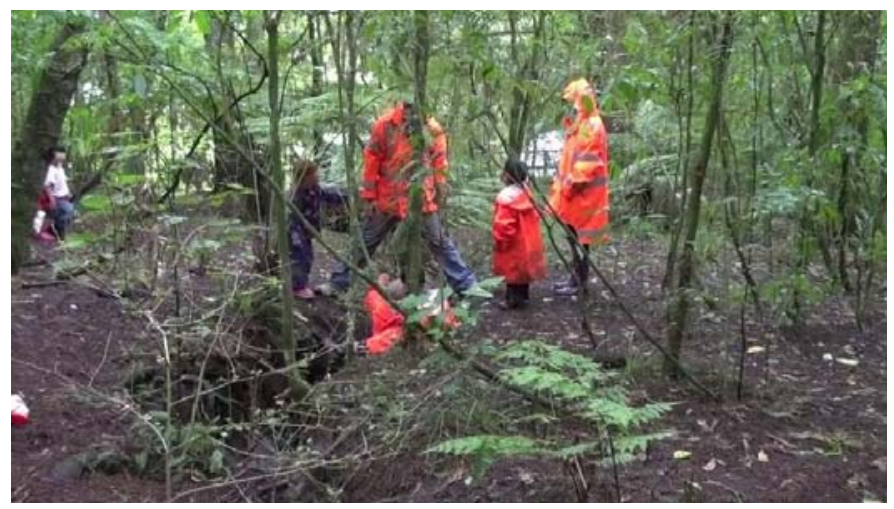

Figure 1. Positioning

This play episode begins with one of the early childhood teachers, Tim, positioning himself astride a 'pit' in the forest floor (see Figure 1). The children have shown much interest in using this natural topography to climb in and out of and have built it into their pretend play of 'mud-monsters' where they attend to the environmental feature as the mud monster's home. In the photograph (see Figure 1), we see Tim demonstrating his noticing of the children's interest in the environmental feature to co-produce this pretend play activity and that he has recognised an opportunity for his collaboration in this play, responding by positioning himself astride the pit. In doing so, Tim actively engages in facilitating learning experiences for these children through noticing, recognizing, and responding as promoted in the Well-being Strand of Te Whāriki "Kaiako support young children to respond to challenge, take risks, and undertake new endeavors" (MOE, 2017, p. 29). This is achieved in playful ways that are meaningful to the children as Tim joins in the mud monster game. His physical position affords multiple engagements with all of the 
children immediately present, inviting a choreography and "framework for mutual orientation" (Goodwin \& Cekaite, 2013, p. 124).

Showing an interest: Transcription 1(Cloe - @01:02). The following interaction is initiated by Cloe who is drawn to Tim's stance and the interaction. He is currently engaged in with other preschool children. In this ongoing interaction, Tim is playing a game of 'mud-monsters' where he is lowering the 'mud-monster' children into the 'pit'. Cloe stands next to Tim and watches this interaction for a few seconds before asking Tim if he can do the same activity with her, which he does.

01 Cloe: Tim (0.4) c- (0.6) can [you do ${ }_{-}^{-}$

02 Sam: [can't=get=me=mud-monster

03 Tim: ((lifts Sam up and lowers him gently into the pit))

04 teach: [hah hah

05 Sam: [argh::.::

06 Cloe: [can you do that to me;

07 Tim: ((continues lowering Sam))

08 Cloe: can you do that to me; Tim ((reaches arms out - Tim

09 immediately holds her hands)) (Figure 2)

10 Tim: ((lifts Cloe up and lowers her into the pit))

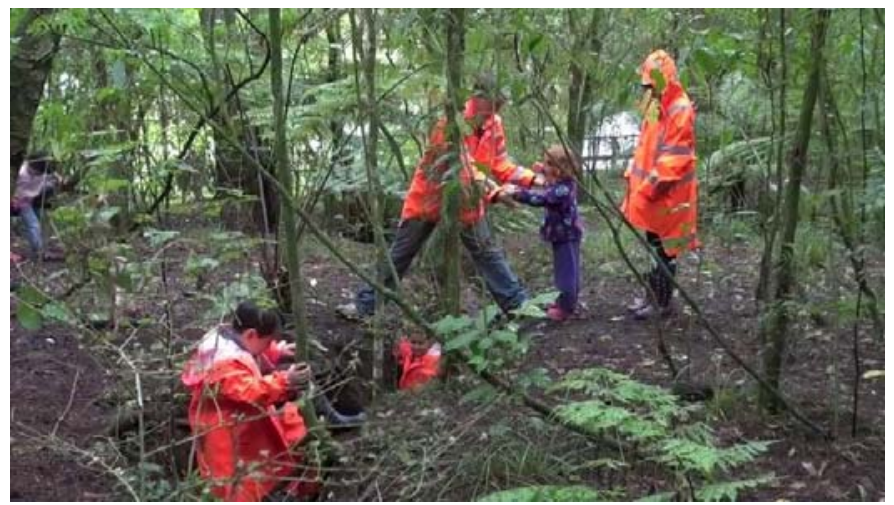

Figure 2. Lines 08 \& 09 of Transcript 
Cloe shows her interest in being involved in the game through moving towards Tim and calling his name to ensure his attention. She begins to ask him a question, but then cuts off her sentence to allow Sam to speak. Once Sam has finished speaking, but before Tim has finished responding to him by lowering him into the pit, Cloe begins her question again, showing her eagerness to be involved in the play. Cloe then repeats her question to Tim, placing intonation on his name at the end of the question this time to ensure his attention and holding her arms out (line 08). Through these actions, Cloe displays her willingness to be involved in multi-modal ways through both verbal actions and gesture (Goodwin \& Goodwin, 2000). Cloe's actions are responded to positively by Tim in his next move where he immediately reaches to hold her hands (see Figure 2). This initial interaction marks Cloe's interest in engaging with the play and the environmental feature, but not in crossing the ditch, just in being lowered into it at this stage. The collaborative actions of Tim and Cloe here demonstrate mutual engagement in the activity (Goffman, 1981) centred around an environment feature.

Showing an interest: Transcription 2 (Hannah @01.52). Tim is still in the same position astride the pit, lowering children in on their request as with the prior transcription (see Transcription 1). Hannah now stands next to Tim, observing his interactions with the other children for a few seconds before asking to participate.

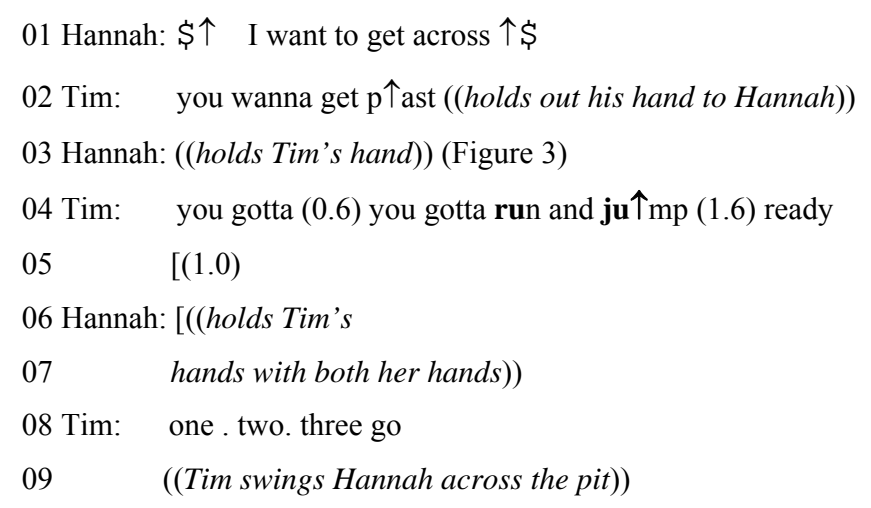




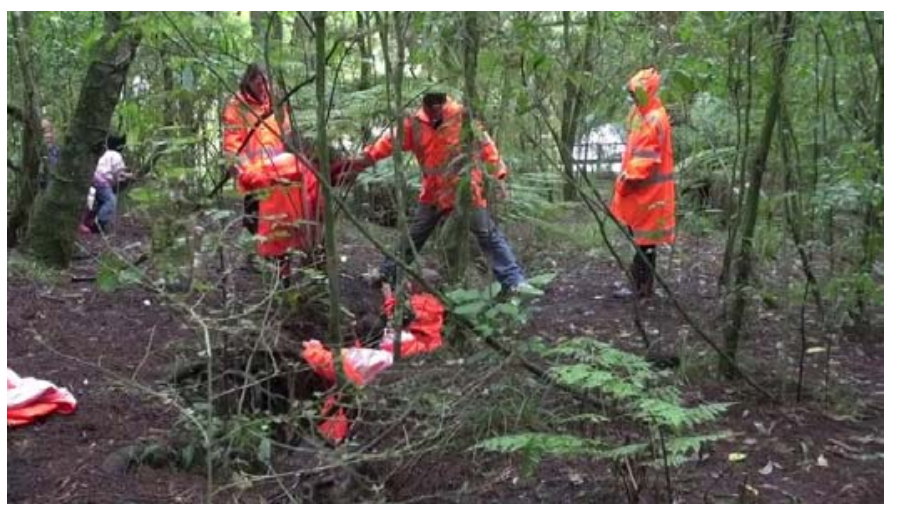

Figure 3. Line 03 of Transcript

In a similar way to the first sign of interest from Cloe (see Transcription 1), Hannah now stands next to Tim and observes him for a while before speaking. Hannah initiates an interaction with Tim, using a high intonation in her voice and smiling while she speaks, talking in what can be observed as a playful way where emotions are high (Goodwin \& Goodwin, 2000). Interestingly, rather than asking Tim directly for help across the pit, Hannah makes a statement 'I want to get across' marking Hannah's desire (want) to get across the pit as a 'declarative statement about the action that needs to be done' (Goodwin \& Cekaite, 2013, p. 126) rather than an explicit request for help. Hannah has described her want (her trouble) as a way of eliciting an offer from Tim without being accountable for asking for help so that she is 'able to recruit the agency of another without being accountable for having done so' (Sidnell, 2017, p. 94) and so distributes the agency of the upcoming action. Tim responds in a way that addresses Hannah's required action needing to be done - to 'get past' - and holds his hand out towards her, which she accepts. Tim then offers a strategy to Hannah regarding how to cross, placing emphasis on the words run and jump (line 04), suggesting to Hannah how she can perform the crossing action, and so avoiding doing all the crossing for her. Tim then leaves a brief pause before 'ready' and then another brief pause, at which point Hannah clasps his hands with both of hers. Another primer is then used by Tim 'one, two, three go' (line 07) before he and Hannah use their bodies in a collaborative way to swing Hannah across the pit, as a joint project, where Hannah contributes fully to the activity.

In this interaction, we see the collaborative action of Hannah and Tim working together 
to cross the pit, affording Hannah a meaningful contribution in the crossing, and so achieving some confidence in her own abilities during the risk taking. We suggest that Tim has recognized Hannah's 'zone of proximal development' (Vygotsky, 1978, p. 86) in relation to making an independent crossing of the pit; that is, she cannot do this alone, but has the capacity, if supported, and wishes to undertake the risk involved in getting across the pit. Tim works within Hannah's ZPD to ensure she is encouraged and supported while also engaging in risk taking and stretching one step ahead of her current comfortable ability.

\section{Showing an interest: Transcription 3 (@02.11).}

01 Cloe: ( ) I want to go over that side::

02 Tim: ((holds Cloe’s hand) $) \downarrow$ alright $(0.1)$ ready: $(0.5)$ set

$03 \quad(0.2)$ go; $=$

04 Cloe: $=((j u m p s$ across the ditch holding Tim's hand $))$

...some lines of talk omitted...

05 Cloe: ((holds hand out towards Tim)) do that agai::n

06 Tim: ((takes Cloe's hand))

07 Hannah: do I get a pa::ss;

08 Cloe: ((jumps across holding Tim's hand))

09 Tim: ((left hand reaches to Hannah which she receives with

10 both hands))

$11 \quad[(($ Hannah swings across holding Tim's hand $))$

12 Cloe: [do that $\mathrm{a} \uparrow$ gain;

13 Hannah: ((lands and Tim takes his left hand away from her))

14 Cloe: do that ag[ain;

15 Hannah: [ $\downarrow$ wow

16 ((Cloe swings across holding Tim's hand. When he lets

17 ((Cloe swings across holding Tim's hand. When he lets

18 of her hands again, and he swings her back across, this

19 time higher. Hannah twists as she lands and Tim moves his 
20 right hand to steady her))

21 Hannah: $\$ \uparrow$ eeee : : : \$

Both Cloe and Hannah are now together next to Tim. In a similar way to Hannah in Transcript 2, Cloe now makes a declarative statement about crossing rather than asking Tim to do an action for her as she had originally done in Transcription 1. Cloe's statement identification of a desired action to be accomplished (Goodwin \& Cekaite, 2013) works to place independence and ownership of the risk taking back to Cloe as she does not explicitly state that she needs Tim's help and so is still recognizable as a competent collaborator (Sidnell, 2017). Tim offers adult support through his continued positioning astride the pit (see Figure 1) and through the same preparation strategy for the transition across the pit he gave to Hannah earlier with "one, two, three", this time with "ready, set, go" (line 2). The preparation strategy that Tim initiates here aligns with recommended practice identified in Te Whāriki where early childhood teachers "should encourage children to know what is happening and why" (MOE, 1996, p. 83). Through preparing Hannah for what is about to happen using this verbal strategy, Tim is able to scaffold her confidence in risk-taking by demonstrating verbally and physically that crossing the pit can be accomplished in a successful way through a predictable sequence of actions. With this support, Cloe jumps across the pit holding Tim's hand with both parties working collaboratively on the transition. Tim's lifting, swinging and carrying action, and the co-operative movements from the children to make this happen demonstrate "the child's embodied 'trust' in the adult's physical strength and embodied support while also enacting the adult's embodied control" (Goodwin \& Cekaite, 2018, p. 23).

The next lines of interaction (05-19) demonstrate a fluid choreography of movement between Tim, Cloe, and Hannah. The prior trusting interactions around the risk-taking mark a sequential progression in the reduction of the amount of adult support needed for the crossing in the next actions where Tim subsequently abandons the preparation strategy of verbal cues prior to crossing and just physically helps them over (lines 9-11). Much less time is spent on the crossings and the girls move more freely across the pit, one after the other. Towards the end of the interaction, although Hannah still holds on with two hands showing possible less confidence, Tim lifts Hannah much higher over the pit, resulting in 
more of a risk as she twists in her landing and screeches while smiling (lines 17-19). This escalation of excitement is charged by well supported but increasingly challenging risktaking. Throughout the children's persistence with the challenging task, the teacher responds to their increasing confidence through offering less preparation prior to a jump, quicker jumps and adding more risk (lifting higher), so, we would argue, building resilience. The interactions that are afforded relate to jumping over the pit with increasing selfconfidence, experiencing a thrill of extreme physical challenge, and 'crying out with pleasure', all 'signals' of extremely high wellbeing on the Leuven wellbeing scale (Laevers, 2000).

Showing an interest: Transcription 4 (@6.00). Tim is standing astride the pit further up now. Cloe and Hannah have been running around the bush area and have now come running towards Tim.

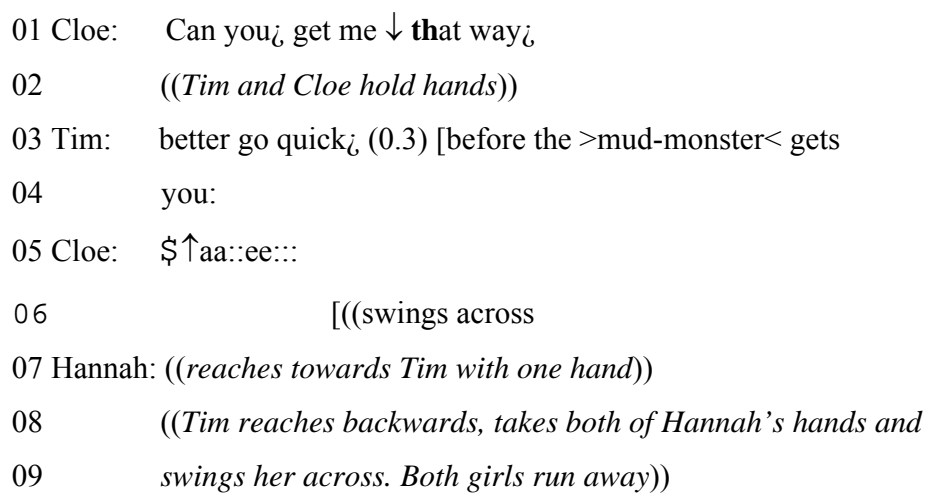

The pace of the crossing now speeds up considerably as Cloe and Hannah run towards Tim, with Cloe asking Tim if he can "get her that way". Tim's response is very quick, afforded by his bodily position astride the pit as he takes Cloe's hand and attends to the immediacy of the situation with added excitement of the mud-monster getting her (line 3). This prompts squeals of delight from Cloe as she quickly moves across the pit holding Tim's hand, smiling as she does so. Hannah then shows that she is losing her hesitation prior to jumping the pit as she reaches towards Tim with only one hand this time, showing that she is more confident although Tim does still take both hands. This section of 
interaction (just six minutes after the initial cautious crossings shown in the first transcripts) demonstrates an escalation in confidence around the girls crossing of the pit. Initially, Tim used vocal cues to prepare the girls to jump, including many pauses to stretch out the time of the crossing (see Transcripts 1 and 2), followed by abandoning these strategies in this interaction when the children appeared more confident in their risk-taking (see Transcript 3) to now adding an element of danger and excitement in these latter interactions (lifting Hannah higher and suggesting a mud-monster might get Cloe in this transcript). The sequential progression of confidence at taking risks in these transcripts demonstrates how Cloe and Hannah are building resilience in terms of crossing the pit, all motivated by an inviting outdoor environment and a supportive adult.

Showing an interest: Transcription 5 (@08.17). Cloe is now back with Tim, swinging back and forth over the pit holding Tim's hand. The steadiness of the support from Tim during these crossings become gradually less and less until Cloe is encouraged to cross independently.

01 Tim: whoah!

02 Cloe: ((steadies herself on Tim's leg with her free hand))

03 Tim: you might need to try getting over your $\uparrow$ self Cloe;

04 (0.5) then you won’t even $\uparrow$ need me to be here.

05 Cloe: ((walks towards a tree growing out of the ditch))

06 teach: >probably across there if you hold on to the tree $_{i}<$

$07 \quad(\quad)>\downarrow$ climb in through the trees. you might be able

$08 \quad$ to get across this one $<)$ ((points to a tree))

09 Cloe: ((holds on to the trees and crosses the ditch. Looks back

10 and smiles at teacher))

11 teach: well $\uparrow$ done Cloe.

12 Cloe: $\operatorname{Tim}(0.1)$ I holded on to the $\uparrow$ tree:.

13 Tim: Wow good job Cloe now you don’t need $\uparrow$ me:.

The increasing lack of support strategies is now embodied through Tim's looser physical help offered to Cloe, resulting in her having to steady herself on Tim's leg when she does 
not quite make it across the pit. Cloe uses Tim as a support as she manoeuvres herself largely over the pit. Tim then provides an opportunity for independence as he offers the challenge of crossing herself (lines $3 \& 4$ ). The timing of this challenge in the sequence of the ongoing activity involving the pit is proven to be made just at the right time, shown by Cloe in her response as she walks towards a nearby tree - encouraged by a teacher - and manoeuvres herself across quite competently using the trees as a support. Cloe's new ability to cross the pit herself demonstrates her increased capability and resilience in the face of mild challenge. The teacher positively affirms her effort, further implementing quality teaching practice through the national curriculum framework (MOE, 1996, 2017) and Cloe also recognizes her achievement as she celebrates her accomplishment by drawing Tim's attention to her triumph. Tim responds through further reinforcing her success at independence. The occurrence, throughout these episodes of the signals of high levels of involvement, as set out in the Leuven scale of wellbeing and involvement, indicates children's high levels of wellbeing. We would argue that the process of building resilience through supported risk-taking has contributed to this state of high wellbeing as outlined with reference to Leavers (2000)'s work.

Showing an interest: Transcription 6 (@09.50). During the episode above (see Transcription 5), Hannah was observing Cloe independently climb over the pit and now approaches the same spot where Cloe achieved her independent crossing to try this herself.

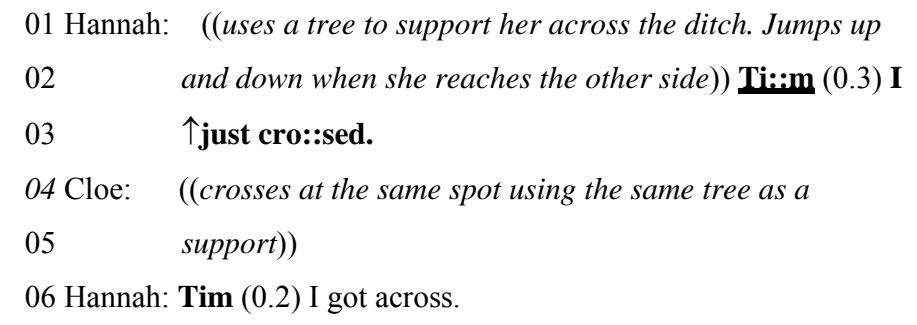

Hannah has observed the success of Cloe crossing the pit using the trees as support and now copies her example by using the same strategy to get herself across in an equally confident way and also celebrates her achievements with Tim by shouting his name and reporting to him. 


\section{Discussion and Conclusion}

It is proposed that what is in evidence here might be conceptualized as physical 'sustained shared thinking' (SST) (Sylva et al., 2004); the extended interaction between Tim and each child can be understood as part of an intentional and responsive pedagogic strategy that supports the co-production of the resulting activity and associated experiences of wellbeing and developing confidence in risk-taking. It is suggested that such physical interactive episodes of SST afford the opportunity for children to develop resilience around risk-taking as is observed by following the sequences of action detailed in the transcripts in this paper.

We propose that what is exemplified in the described interactions between adult and child(ren) within an engaging outdoor environment meets the SST definition (see page 3). We see two (and/or more) individuals working together, physically to solve two related problems posed by the pit, namely, 1) how to get across the pit and 2) how to overcome hesitation in the face of potential risks posed by jumping over the pit. Both Tim and each child contribute to the mutual resolution of these problems; the resolution and subsequent independent activity of the child(ren) indicate that thinking and understanding have been extended as a result. This paper then makes a contribution to the body of work that exemplifies sustained shared thinking as "sustained and shared "moments of activity" (Leontiev, 1978; Siraj-Blatchford, 2009). We emphasize here the sustained and shared physical interaction; Tim has adopted a pedagogic stance that responds to the physical and emotional wants expressed by the children through their interest in the pit. He has 'scaffolded' (Wood et al., 1976) their physical interactions through attention to their emotional needs throughout thus ensuring capable and independent participation by the children in this environment. Such pedagogy is not done to the children, however; we emphasize through the use of the CA analysis and explanation offered, the co-production of these shared moments.

We propose that the new understandings generated as a result of the episode are related to the perceptions held by the children and the staff of the children's physical confidence and competence: their ability to negotiate mild levels of perceived risk and conceive of themselves as capable in the environment. The high levels of involvement observed throughout the episodes indicate that the children were experiencing high levels of 
wellbeing.

The findings reveal the affordances (Gibson, 1979) of the outdoor environment for opportunities for risk-taking and problem solving to arise. They reveal how resilience and wellbeing can be supported through such environments when the adults who shape the permissive space in which the children act (Waters, 2011, 2017) behave in ways that align with children being able to actualize the affordances they perceive in the space (Kyttä, 2004). Here, the environment offered physically challenging opportunities through its natural topography of a narrow pit and trees that surrounded it and elements that the children were drawn to for exploration. The pedagogy adopted by the adults supported the children's playful engagement with these challenging opportunities in ways that allowed the children to take a risk and succeed in overcoming their hesitation in the face of the risks. The children's success was structured, but not dominated by the adult's positioning and showing an interest; as a result, increasing confidence is evident.

As a part of this supportive environment, the teacher here engaged in mutual orientation to the goal of independent crossing with the children through a sequence of actions in playful ways. The support that Tim offered to the children was visible verbally and also physically where he gave just enough support to build up confidence and resilience to take the risk across the pit. The sequential order of provision of support that was tailored to their levels of wellbeing was also observable where the children became more and more confident and less physical support was offered.

The combination of physical and social affordances of the space, therefore, supported the enactment of what we may describe as physical sustained shared thinking. Such social interactions allowed the children to experience behaviors that are associated with contributing to higher levels of coping and resilience: emotional regulation (managing emotions like anxiety or fear); optimistic thinking (which includes feeling some sense of competence and control over one's life and having the confidence to persevere when faced with difficulty); goal-setting skills and associated behaviors such as showing initiative, problem solving skills, and being resourceful; having a sense of autonomy, self-efficacy, and an awareness of one's strengths (Noble \& McGrath, 2012). 


\section{Implications}

The intention to support the development of children's wellbeing and resilience, as important aspects of children's development, is explicit in the New Zealand national curriculum, Te Whāriki. Wellbeing is understood as being an essential element in the relationships existing in education and care settings between children and adults and as a focus for pedagogic activity; as such, it should be supported in context specific ways for each child. The research here demonstrates how the natural outdoor environment and the pedagogy of responsive adults might provide opportunities for such support and development of children's wellbeing through building resilience to risk in meaningful and playful ways.

\section{References}

Anning, A., \& Edwards, A. (2006). Promoting children's learning from birth to five. Maidenhead: Open University Press.

Bateman, A. (2012). Pedagogical intersubjectivity: Teaching and learning conversations between children and teachers. Wellington, New Zealand: NZCER.

Csikszentmihalyi, M. (1990). Flow. New York: Harper \& Row.

Gibson, J. J. (1979). The ecological approach to visual perception. London: Lawrence Erlbaum.

Goffman, E. (1981). Forms of talk. Pennsylvania: University of Pennsylvania.

Goodwin, M. H., \& Cekaite, A. (2013). Calibration in directive/response sequences in family interaction. Journal of Pragmatics, 46(1), 122-138. doi:10.1016/j.pragma. 2012.07.008

Goodwin, M. H., \& Cekaite, A. (2018). Embodied family choreography: Practices of control, care, and creativity. London: Routledge.

Goodwin, M. H, \& Goodwin, C. (2000). Emotion within situated activity. In N. Budwig, I. C. Uzgiris, \& J. Wertsch (Eds.), Communication: An arena of development (pp. 33-53). Stamford: Ablex Publishing

Howes, C., \& Ritchie, S. (1999). Attachment organizations in children with difficult life 
circumstances. Development and Psychopathology, 11(2), 251-268.

Jefferson, G. (2004). Glossary of transcript symbols with an introduction. In G. H. Lerner (Ed.), Conversation analysis: Studies from the first generation (pp. 13-31). Amsterdam: John Benjamins.

Kyttä, M. (2004). The extent of children's independent mobility and the number of actualized affordances as criteria for child-friendly environments. Journal of Environmental Psychology, 24(2), 179-198. doi:10.1016/S0272-4944(03)00073-2

Laevers, F. (1994). The Leuven involvement scale for young children. Leuven: Centre for Experiential Education.

Laevers, F. (2000). Forward to basics! Deep-level learning and the experiential approach. Early Years, 20(2), 20-29. doi:10.1080/0957514000200203

Leontiev, A. (1978). Activity, consciousness, and personality. Englewood Cliffs: Prentice Hall.

Little, H., Wyver, S., \& Gibson, F. (2011). The influence of play context and adult attitudes on young children's physical risk-taking during outdoor play. European Early Childhood Education Research Journal, 19(1), 113-131. doi:10.1080/1350293X. 2011.548959

Maynard, T., Waters, J., \& Clement, J. (2013). Child-initiated learning, the outdoor environment and the 'underachieving' child. Early Years: An International Research Journal, 33(3), 212- 225. doi:10.1080/09575146.2013.771152

Ministry of Education. (1996). Early childhood curriculum. Wellington, New Zealand: Learning Media.

Ministry of Education. (2017). Early childhood curriculum. Wellington, New Zealand: Learning Media.

Newman, T. (2004). What works in building resilience? London: Barnardo's.

Noble, T., \& McGrath, H. (2012). Wellbeing and resilience in young people and the role of positive elationships. In S. Roffey (Ed.), Positive relationships: Evidence based practice across the world (pp. 17-34). London: Springer.

Pianta, R. C., Belsky, J., Vandergrift, N., Houts, R. M., \& Morrison, F. J. (2008). Classroom effects on children's achievement trajectories in elementary school. American Educational Research Journal, 45(2), 365-397. 
Pollard, E. L., \& Lee, P. D. (2002). Child well-being: A systematic review of the literature. Social Indicators Research, 61(1), 59-78. doi:10.1023/A:102128421

Rogoff, B., Mistry, J., Göncü, A., \& Mosier, C. (1993). Guided participation in cultural activity by toddlers and caregivers. Monographs of the Society for Research in Child Development, 58(8), i+iii+v-vi+1-179. doi:10.2307/1166109

Sacks, H., Schegloff, E. A., \& Jefferson, G. (1974). A simplest systematics for the organisation of turn-taking for conversation. Language, 50(4), 696-735.

Sandseter, E. B. H. (2007). Categorising risky play - How can we identify risk-taking in children's play? European Early Childhood Education Research Journal, 15(2), 237252. doi:10.1080/13502930701321733

Sandseter, E. B. H. (2009). Children's expressions of exhilaration and fear in risky play. Contemporary Issues in Early Childhood, 10(2), 92-106.

Sidnell, J. (2017). Distributed agency and action under the radar of accountability. In N. J. Enfield, \& P. Kockelman (Eds.), Distributed agency (pp. 87-96). Oxford: Oxford University Press.

Siraj-Blatchford, I. (2009). Conceptualising progression in the pedagogy of play and sustained shared thinking in early childhood education: A Vygotskian perspective. Education and Child Psychology, 26(2), 77-89.

Siraj, I., Kingston, D., \& Melhuish, T. (2015). Sustained shared thinking and emotional well-being (SSTEW) scale for 2-5 year olds provision. London: IoE Press.

Sylva, K., Melhuish, E. C., Sammons, P., Siraj-Blatchford, I., \& Taggart, B. (2004). The effective provision of pre-school education (EPPE) project: Final report. London, England: DfES Publications. Retrieved from http://eprints.ioe.ac.uk/5309/1/ sylva2004EPPEfinal.pdf

Taggart, B., Sylva, K., Melhuish, E., Sammons, P., \& Siraj, I. (2015, June). Effective preschool, primary and secondary education project (EPPSE 3-16+): How pre-school influences children and young people's attainment and developmental outcomes over time (DFE-RB455 Research Brief). Retrieved from http://dera.ioe.ac.uk/23344/1/ RB455_Effective_pre-school_primary_and_secondary_education_project.pdf

Vygotsky, L. S. (1978). Mind in society: The development of higher psychological processes. Cambridge, MA: Harvard University Press. 
Waller, T., Ärlemalm-Hagsér, E., Sandseter, E. B. H., Lee-Hammond, L., Lekies, K., \& Wyver, S. (2017). The SAGE handbook of outdoor play and learning. London: Sage.

Waters, J. (2011). A sociocultural consideration of child-initiated interaction with teachers in indoor and outdoor spaces (Unpublished doctoral dissertation). Swansea University, Swansea, Wales.

Waters, J. (2017). Affordance theory. In T. Waller, E. Ärlemalm-Hagsér, E. B. H. Sandseter, L. Lee-Hammond, K. Lekies, \& S. Wyver (Eds.), The SAGE handbook of outdoor play and learning (pp. 40-54). London: Sage.

Waters, J., \& Bateman, A. (2013). Revealing the interactional features of learning and teaching moments in outdoor activity. European Early Childhood Education Research Journal, 21(3), 1-13. doi:10.1080/1350293X.2013.798099

Wood, D., Bruner, J., \& Ross, G. (1976). The role of tutoring in problem solving. Journal of Child Psychology and Psychiatry, 17(2), 89-100. doi:10.1111/j.14697610.1976.tb00381.x 